\title{
Benchmarking SCM performance and empirical analysis: a case from paint industry
}

\author{
Pratima Mishra • Rajiv Kumar Sharma
}

Received: 23 May 2013/Accepted: 6 March 2014/Published online: 26 March 2014

(C) The Author(s) 2014. This article is published with open access at Springerlink.com

\begin{abstract}
The real challenge for managers is to develop and implement a suitable supply chain performance framework that not only helps in making right decisions but also facilitates the benchmarking of their internal supply chain. The main purpose of this study was to develop a framework based on the performance metrics such as (1) total length of the supply chain, (2) supply chain inefficiency ratio and (3) supply chain working capital productivity. Case study approach is used to benchmark the SCM performance of two paint companies. Further, in order to examine the relationship between SCM practices and SCM performance measures, an empirical analysis has been done by formulating research hypothesis. Results show strong support for linkage between SCM practices and selected performance metrics.
\end{abstract}

Keywords Supply chain - SCM performance .

Benchmark $\cdot$ SCM practices

\section{Introduction}

In the recent years, a number of firms have realized the potential of SCM in day-to-day operation management but evaluating SCM performance is a complex task, because it involves several dimensions be it strategic, tactical or

P. Mishra $(\bowtie) \cdot$ R. K. Sharma

Department of Management and Social Sciences, National Institute of Technology, Hamirpur, HP, India

e-mail: pratima_mishra1@ rediffmail.com

R. K. Sharma

Mechanical Engineering Department, National Institute

of Technology, Hamirpur, HP, India

e-mail: rksnithmr@gmail.com operational. According to the Shah [39], supply chain management encompasses all activities involved in the transformation of goods from the raw material stage to the final stage when the goods and services reach to the end customer. In order to attain competitive advantage over the rivals, various business houses are paying more attention towards the end consumer, i.e. customer. A key feature of present day business is the idea that it is the supply chain that competes, not companies, and the success or failure of supply chain is ultimately determined in the marketplace by the end consumer [14]. Brandenburg and Seuring [9] applied benchmarking methodology for quantifying value contributions in terms of cost of goods sold and working capital from ten leading fast-moving consumer goods companies. They further emphasized on cross-industry benchmarking with different or extended content which may include key supply chain partners, i.e. suppliers, service providers, retailers and distributors. Previous researches [4, 19, 23, 26, 46] into supply chain benchmarking show that it may lead to increased productivity of the supply chain, as managers compare their practices to the best in the field.

Many researchers have stressed the importance of using the right metrics to benchmark and manage supply chain efficiently and effectively [1, 12, 21, 28, 34]. Gunasekaran et al [21, 22], Hudson et al. [24], Folan and Browne [18] identified key SCM metrics and proposed a framework to classify them as financial and non-financial metrics. In the literature, various models such as (1) analytic hierarchy process (AHP), (2) balanced scorecard (BSC) and (3) supply chain operations and reference model (SCOR) were developed for supply chain performance evaluation. According to Bhagwat and Sharma [7], AHP can be the best tool for prioritizing and choosing the best measure and metric for day-to-day business operations. However, it is argued that AHP is not stable in its theoretical foundation 
and could cause revision in decision-maker's preference because pairwise comparison metric fails to perfectly satisfy the consistency required by the AHP approach [11]. BSC was first introduced by Kaplan and Norton in year [25]. It consists of four perspectives: (1) financial, (2) customers, (3) internal business process, (4) innovation and learning. Bhagwat and Sharma [6] suggested putting different SCM metrics into different BSC perspectives to give a balanced picture of SCM performance evaluation. Further, they (Bhagwat and Sharma [7]) expanded the BSC framework to include AHP in determining which measures to include and at which level (strategic, tactical or operational) of the organization. Criticism of the BSC includes the exclusion of people, competitive environments, environmental and social aspects of industry [3,36]. Epstein and Weisner [17] argued that there is no rule for the right number of measures to include in a balanced scorecard, although including too many can distract from pursuing a focused strategy. In a review conducted by [20], they concluded that BSC is more like a strategic tool rather than a true complete performance measurement system. SCOR was developed by the Supply Chain Council. It defines supply chain as the integrated process of plan, source, make, deliver and return. It contains five level of analysis, i.e. (1) process type, (2) process categories, (3) process elements, (4) implementation and (5) performance metrics. However, measurement models for supply chain performance evaluation have their limitations. Firstly, there are too many individual measures being used in the supply chain context. For example, Shepherd and Gunter [40] have summarized single supply chain performance indicators related to cost (39), time (22), quality (or reliability) (35), flexibility (28) and innovativeness (8), respectively. Though these measures offer valuable information for decision making, selecting and trading off so many measures to obtain effective and crucial improvement strategies is a difficult task for different supply chain participants. Secondly, these models do not provide definite cause-effect relationships among numerous (and hierarchical) individual key performance indicators [10]. According to Persoon and Araldi [35], SCOR is basically used for the static operations of supply chain rather than the dynamic effects like changes in production rate, poor quality in raw materials and other effects related to the bullwhip behaviour of a supply chain.

With all these problems highlighted with reference to AHP, BSC and SCOR models, there seems to be no universal consensus regarding suitable measures of SCM performance. Cai et al. [10] in their work found that many measurement systems lacked strategic alignment, a balanced approach and universal thinking; they have difficulty in systematically identifying the most appropriate metrics. According to Martin and Patterson [30], firms that were engaged in SCM found inventory and cycle time to be the most significant metrics, but the dimensions related to inefficiency and working capital productivity are not addressed adequately. There are many metrics considered by different authors like cost, quality, flexibility, innovation and responsiveness [5, 12, 21, 22, 40], but they lack consideration of inefficiency ratio, total length of supply chain and working capital productivity. Work by Wouters and Wilderom [47] and Wouters [48] clearly supported the need for a performance measurement system which should clearly define the purpose, data collection and calculation methods, and simple, easy to use, preferably in the form of ratios rather than absolute numbers. Studies in the past have shown that a well-planned and executed SCM will not only enable organizations to reduce their inventories, but also provide better customer services [13]. On one hand, SCM's short-term objective is targeted to enhance productivity and reduce inventory and lead time, and on the other hand, the long-term objective is targeted to increase company's market share and have external integration of the supply chain processes, which needs to be further investigated [27, 29]. Also, Akyuz and Erkan [1] in their paper on "supply chain performance measurement: a literature review" concluded about immaturity of SCM frameworks and models in their survey and believed that future contribution to the area will come specifically from framework development efforts and validation of developed performance measures.

To abridge this gap, authors in the present study developed a benchmarking framework based upon performance metrics given by Shah [39]. In the first part of work, SCM performance of two paint companies is benchmarked and DMAIC approach is explained which takes care of all entities, i.e. supplier, distributor and retailer in a supply chain network. In the second part, empirical testing of the selected performance metrics is done by formulating various research hypothesis.

The organization of this paper is as follows. After introduction in Sect. 1, the Sect. 2 briefly describes the theoretical background with research framework and formulas of metrics considered in the work. The Sect. 3 presents the research objectives and methodology. The Sect. 4 discusses the analytical approach adopted in the study. Empirical analysis based on various research hypotheses formulated in the study is presented in the Sect. 5. The discussions and theoretical implications are presented in Sect. 6. Finally, concluding remarks and directions for future research are given in Sect. 7.

\section{Theoretical background}

The section presents summary of some significant findings with reference to supply chain performance measurement 
which takes into account (1) supply chain length (2) supply chain inefficiency ratio and (3) working capital productivity with both theoretical and practical listing of related literature (Table 1).

Having outlined the detailed interpretation of related literature and necessary research gaps, the framework (Fig. 1) and important formulas to measure the selected performance metrics, i.e. (1) total length of the supply chain, (2) supply chain inefficiency ratio and (3) supply chain working capital productivity, are discussed as under (Shah [39], Sriyogi [43]). Various indicators used in performance metrics are presented in Fig. 2.

(1) Total length of the supply chain-The total length of the supply chain is [given by Eq. (4)] arrived at by adding up the days of inventory for raw materials (DRM), days of work in progress (DWIP) and days of finished goods (DFG). The firm that has the minimum total length of the chain is said to have best performance.

Table 1 Summary of literature findings

\begin{tabular}{ll}
\hline $\begin{array}{l}\text { Author and year of } \\
\text { publication }\end{array}$ & Category objectives/Research gaps \\
\hline
\end{tabular}

$\begin{aligned} & \text { Shah and Singh } \\ & \text { Theoretical (performance } \\ & \text { measures) }\end{aligned}$

Elmuti [16]
Theoretical (performance measures)

Basnet et al. [4] Practical (case study)

Dangayach and Theoretical (survey study)
Deshmukh [15]
Gunasekaran et al. Theoretical (performance
[22] measures metrics)

Sridharan et al. Practical (case study)
[44]

Singh et al. [41] Practical (performance measures) $\begin{gathered}\text { Wong and Wong Theoretical (performance } \\ \text { [46] }\end{gathered}$
measures)
Soni and Kodali Theoretical (performance [42]

Arlbjorn et al. [2] Conceptual (exploratory study)
Authors proposed (1) supply chain length (2) supply chain inefficiency ratio (3) working capital productivity as benchmarking metrics for internal supply chain performance. Work can be extended by performing empirical investigations to validate the results.

Studied the impact of SCM on overall organizational effectiveness and identified problems affecting SCM success and found that the firms implement SCM are to reduce cost, inventory and cycle time, which needs to be further investigated by considering suitable SCM performance metrics in different supply chains.

This paper illustrated an empirical study of benchmarking on supply chain practices in New Zealand. Further work for identification and validation of SCM practices particularly suited to manufacturing industries is required.

Authors stressed that Indian industry is facing competition both from imports and from multinational companies in the domestic market because new competition is in terms of improved quality, products with higher performance, reduced cost, a wider range of products, and better service, all delivered simultaneously but they failed to deliver on time, so it needs to reduce the length of the supply chain by analysing the supply chain network.

Authors have concluded that many companies have not succeeded in maximizing their supply chain's potential because they have often failed to develop the performance measures and metrics needed to fully integrate their supply chain to maximize effectiveness and efficiency.

Authors conducted a practical study to investigate supply chain implementation issues that could have major impact on the value of firms which is otherwise the capital productivity of firms. The issue has been addressed along with length and inefficiency in a paint supply chain by us as one of the important SCM metrics.

Authors utilized benchmarking and performance measurement to investigate SCM practices at a number Indian manufacturing organizations by considering different metrics such as improving on time delivery, reducing inventory costs, to secure supply of raw materials and components, lowest possible product cost, reducing order to delivery cycle time, integrating suppliers, etc. and stressed the need for further analysis.

Authors focused on the past literature of supply chain benchmarking and found that most of the past literature had not viewed supply chain as whole entity and there is a scarce of empirical studies. So, authors in the present study has focused on the benchmarking and empirical study by considering three metrics, i.e. length, inefficiency ratio and capital productivity.

Authors proposed a methodology for the internal benchmarking to reduce the variability in performance among supply chain of same focal firms by considering a case study and stressed the need to develop a framework which can measure length and inefficiency of a supply chain.

Authors presented exploratory studies that aim to provide a better understanding of supply chain innovation, mirroring leading edge practices, and providing a sound terminological and conceptual basis for advanced academic work in the field. Author emphasized that there is a lack of common terminology of agreement about the conceptual understanding of key performance metrics, and of related empirical work related to SCM performance which needs to be abridged. 


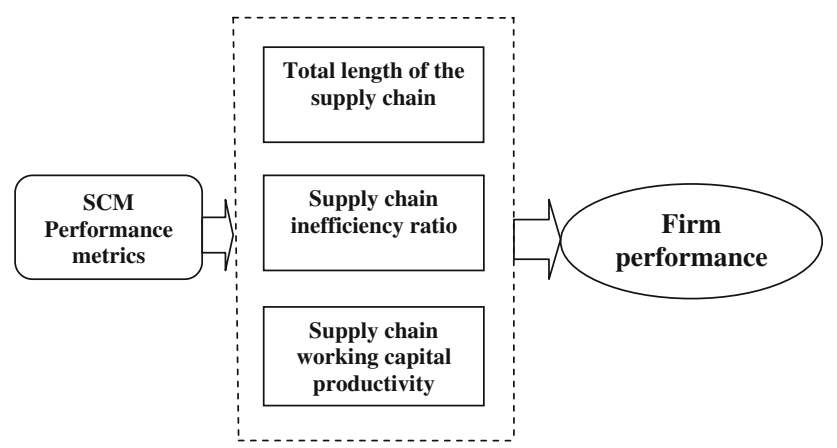

Fig. 1 Research framework

$\mathrm{DRM}_{i}=\frac{\mathrm{RM}_{i} \times 365}{\mathrm{CRM}_{i}}$

where $i=$ index for time period which is taken as a year (i.e. 365 days) $\mathrm{DRM}_{i}=$ days of raw material inventory for time period $i \mathrm{RM}_{i}=$ raw material inventory for time period $i \mathrm{CRM}_{i}=$ cost of raw material for time period $i$

$\mathrm{DWIP}_{i}=\frac{\mathrm{SFG}_{i} \times 365}{\mathrm{CP}_{i}}$

where $\mathrm{DWIP}_{i}=$ days of work in process inventory for time period $i \mathrm{SFG}_{i}=$ semi-finished goods inventory for time period $i \mathrm{CP}_{i}=$ cost of production for time period $i$

$\mathrm{DFG}_{i}=\frac{\mathrm{FG}_{i} \times 365}{\mathrm{CS}_{i}}$

where $\mathrm{DFG}_{i}=$ days of finished goods inventory for time period $i \mathrm{FG}_{i}=$ finished goods inventory for time period $i \mathrm{CS}_{i}=$ cost of sales for time period $i$

Total length of the chain (in days)

$=\mathrm{DRM}_{i}+\mathrm{DWIP}_{i}+\mathrm{DFG}_{i}$.
Cost of raw material is the total cost of raw material consumed during the accounting period. It also includes incidental expenses for procuring raw materials. In this paper, cost of raw material value is directly considered from financial statement and is represented by CRM.

(2) Supply chain inefficiency ratio-This ratio measures the relative efficiency of internal supply chain management. The ratio will be low for the firms with better performance.

$\mathrm{SCI}_{i}=\frac{\mathrm{SCC}_{i}}{\mathrm{NS}_{i}}$

$\mathrm{SCC}_{i}=\mathrm{DC}_{i}+\mathrm{INV}_{i} \times \mathrm{ICC}_{i}$

where (1) $\mathrm{SCI}_{i}=$ supply chain inefficiency ratio for the time period $i$ (2) $\mathrm{SCC}_{i}=$ supply chain management costs for the time period $i$ (3) $\mathrm{DC}_{i}=$ distribution cost for the time period $i$ (4) $\mathrm{ICC}_{i}=$ inventory carrying cost percentage for the time period $i(5) \mathrm{INV}_{i}=$ inventory for the time period $i(6) \mathrm{NS}_{i}=$ net sales for the time period $i$.

This measure is known as the internal supply chain inefficiency ratio since the internal supply chain management cost would be higher if the operations are not optimal and there is inefficiency in the system. Distribution cost includes the expenses incurred in transportation and material handling. To have an efficient and flexible distribution, firms try to achieve optimization in activities related to transportation, loading, unloading and warehousing. The firms that manage their internal supply chain processes in an efficient manner will have lower levels of inventory. The lower level inventory is achieved by better purchasing, planning, manufacturing and distribution processes [43].

(3) Supply chain working capital productivity-The analysis of firms on these metrics will also be based on the level of inventory, accounts receivable and accounts

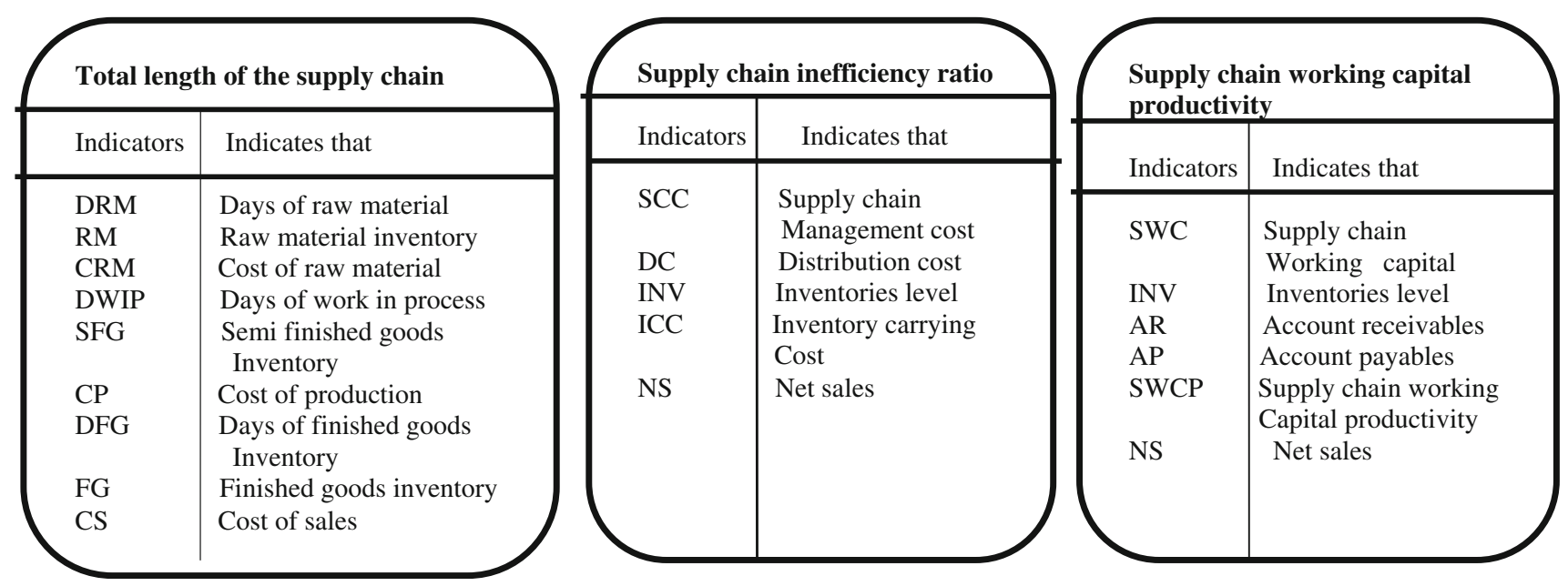

Fig. 2 Indicators of performance measurement metrics 
payable. Firms with efficient supply chains will have high supply chain working capital productivity.

$\mathrm{SWC}_{i}=\mathrm{INV}_{i}+\mathrm{AR}_{i}-\mathrm{AP}_{i}$

where $\mathrm{SWC}_{i}=$ supply chain working capital for the time period $i \mathrm{INV}_{i}=$ inventory for the time period $i \mathrm{AR}_{i}=$ accounts receivable from the dealers/distributors for the time period $i \mathrm{AP}_{i}=$ accounts payable to the suppliers from the time period $i$

$\mathrm{SWCP}_{i}=\frac{\mathrm{NS}_{i}}{\mathrm{SWC}_{i}}$

where $\mathrm{SWCP}_{i}=$ supply chain working capital productivity for the time period $i \mathrm{NS}_{i}=$ net sales for the time period $i$.

Accounts receivable is termed as sundry creditors in the public databases. These are basically the distributors and the dealers who buy the products and owe payment to the firm.

Inventory is a composite of raw materials, semi-finished goods and finished goods inventories. Accounts payable is termed as sundry debtors in the public data bases. These are basically the suppliers of raw materials to whom the firm owes payment.

\section{Research methodology}

The section provides details regarding the research objectives/solution methodology along with description of case settings/environment. The following research objectives have been deduced for the study:

(1) To benchmark the SCM performance based upon metrics, i.e. (a) total length of the supply chain, (b) supply chain inefficiency ratio and (c) supply chain working capital productivity.

(2) To find out correlation between performance measures and SCM practices.

(3) To empirically test the relationship between SCM practices and performance measures by formulating various hypothesis.

(4) To see whether significant difference with respect to selected metrics exists between SCM firms and non-SCM firms.

A framework to measure SCM performance based upon two independent approaches, i.e. (1) analytical approach to benchmark and compute SCM performance metrics based on company data (2) empirical approach based upon hypothesis formulation and statistical validation. In the first approach, two paint companies (detail discussed in Sect. 4) have been considered and data related to performance metrics, i.e. (1) total length of the supply chain; (2) supply chain inefficiency ratio; and (3) supply chain working capital productivity is used to benchmark the performance of supply chain. DMAIC (Define-Measure-AnalyseImprove and Control), a six sigma process is used to identify and analyse the problems for improving SCM performance metrics.

Further, in order to examine the relationship between best SCM practices and SCM performance measures, empirical analysis has been done by formulating various research hypotheses, i.e. (H1-H6).

H1 The use of good SCM practices results in improving the total length of the supply chain.

H2 SCM practices helps to decrease the supply chain inefficiency ratio.

H3 SCM practices have positive effect on the supply chain working capital productivity.

H4 Firms those employing SCM practices will perceive that their total length of the chain is better than those do not employing SCM practices.

H5 Firms those employing SCM practices will perceive that their inefficiency ratio is better than those do not employing SCM practices.

H6 Firms those employing SCM practices will perceive that their supply chain working capital productivity is better than those do not employing SCM practices.

The case settings are described in the paragraph as under:

A structured questionnaire ("Appendix 2") was designed based on the initial feedback received against a pilot questionnaire and subsequent personal interactions held with academicians, and people from paint companies in the Northern region of the country. In order to measure the variables of firm performance metrics, the questionnaire used a six-point Likert scale for supply chain practices in general and specifically mentioned the terms related to total length of the chain, supply chain inefficiency ratio and supply chain working capital productivity. In order to define the firms that are using SCM or not, a dichotomous variable was used that expressed either the existence of SCM (1) or without SCM (2). The sample was selected randomly. Firms with less than 250 employees were considered as SMEs. A total of 150 questionnaires were mailed and sent out to the companies. The respondents were followed up by phone and mail to increase the response rate. A total of 60 usable surveys were received representing a response rate of $40 \%$. From the 60 responses, 45 were employing SCM practices and the remaining 15 were not employing SCM practices. Table 2 presents the distribution of the respondents by firm size. 
Table 2 The distribution of the respondents by firm size

\begin{tabular}{llll}
\hline $\begin{array}{l}\text { Number of } \\
\text { employee }\end{array}$ & $\begin{array}{l}\text { Number of } \\
\text { respondent }\end{array}$ & Percent & $\begin{array}{l}\text { Cumulative } \\
\text { percent }\end{array}$ \\
\hline $0 \leq 50$ & 6 & 10 & 10 \\
$>50 \leq 100$ & 9 & 15 & 25 \\
$>100 \leq 150$ & 13 & 21.67 & 46.67 \\
$>150 \leq 200$ & 12 & 20 & 66.67 \\
$>200 \leq 250$ & 15 & 25 & 91.67 \\
$>250 \leq 300$ & 5 & 8.33 & 100.00 \\
\hline
\end{tabular}

Table 3 SCM performance metrics calculation for year 2005-2006

\begin{tabular}{llc}
\hline Total length of supply chain (in days) & Company A & 106.09 \\
& Company B & 160.54 \\
Supply chain inefficiency ratio & Company A & 0.0648 \\
& Company B & 0.088 \\
Working capital productivity of SCM & Company A & 7.65 \\
& Company B & 4.57 \\
\hline
\end{tabular}

\section{Case study analytical approach}

A case from paint industry situated in Northern part of India is under taken to describe the framework and validate the performance measures. The cost data of two paint companies is collected from the annual report of the paint companies for financial year 2005-2006 to financial year 2009-2010 (shown in "Appendix 1"), and benchmarking exercise between two companies is done by measuring the metrics, i.e. total length of the supply chain, inefficiency ratio and working capital productivity metrics.

Based upon cost data extracted from the financial report of companies, length of the supply chain, supply chain inefficiency ratio and supply chain working capital productivity for both companies are calculated using the formulas listed in Sect. 2 for financial year (2005-2006) as presented in the Table 3.

The yearwise comparison of financial year from 2005-2006 to 2009-2010 for all the three metrics is shown in Figs. 3, 4, 5. As shown in the Fig. 3, company A is having the minimum length as compared to company $\mathrm{B}$. The company A has maintained the total length, but the company B is having more length during period 2005-2006 which was about 160 days which increased 170 days in year 2006-2007 and further dropped to 132 days in year 2008-2009. This implies that supply chain length for process of raw material, semi-finished goods and finished goods is not balanced properly. The company A following good SCM practices is having less total length of the chain throughout the years. So, according to the trend in Fig. 3, company A is performing better.

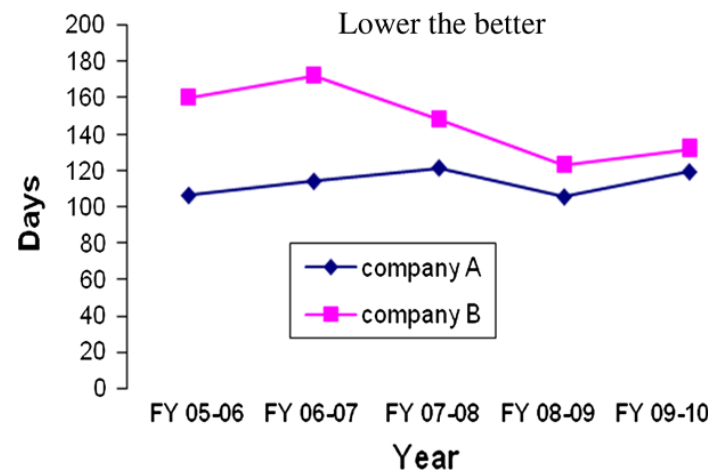

Fig. 3 Yearwise comparison of total length of supply chain

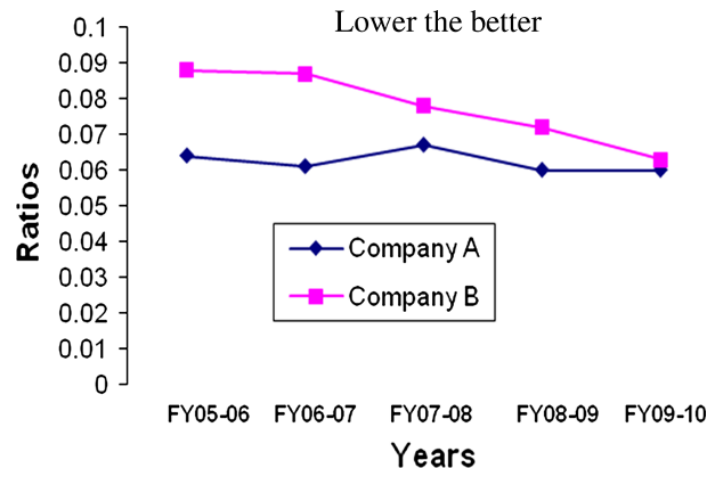

Fig. 4 Yearwise comparison of supply chain inefficiency ratio

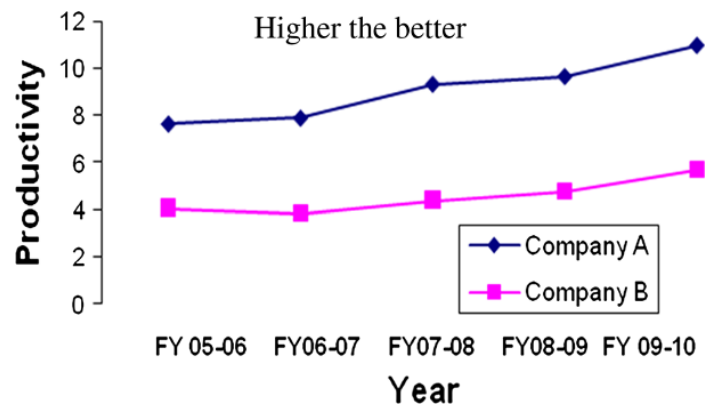

Fig. 5 Yearwise comparison of supply chain working capital productivity

As shown in the Fig. 4, the company $\mathrm{A}$ is having less inefficiency ratio than company B. But after that, company B somehow manages to reduce his ratio. It was about 0.088 in year 2005-2006 and then it decreased to 0.087 in year 2006-2007, but after that, it dropped to between 0.07 and 0.06 in year 2008-2009 and year 2009-2010. It shows that they have tried to manage inventory cost as well as distribution cost.

Figure 5 shows the comparison of the supply chain working capital productivity of the companies. It is expected that if the company is improving the total length as well as the inefficiency ratio, then the productivity of the 
Table 4 Definition and tools used in DMAIC process

\begin{tabular}{|c|c|c|}
\hline Phases & Definitions & Tools used \\
\hline Define & $\begin{array}{l}\text { What is the problem? Does } \\
\text { it exist? What type of } \\
\text { defects exists? }\end{array}$ & $\begin{array}{l}\text { SIPOC diagram, data } \\
\text { collection, brainstorming, } \\
\text { voice of customer, Pareto } \\
\text { chart }\end{array}$ \\
\hline Measure & $\begin{array}{l}\text { How is the process } \\
\text { measured? How is it } \\
\text { performing? }\end{array}$ & $\begin{array}{l}\text { Data collection, } \\
\text { brainstorming, histogram/ } \\
\text { frequency plot, }\end{array}$ \\
\hline Analyse & $\begin{array}{l}\text { What are the most } \\
\text { important causes of } \\
\text { defects? }\end{array}$ & $\begin{array}{l}\text { Cause and effect analysis, } \\
\text { SPC run chart, } t \text { test, } \\
\text { ANOVA test }\end{array}$ \\
\hline Improve & $\begin{array}{l}\text { How do we remove the } \\
\text { causes of defects? }\end{array}$ & $\begin{array}{l}\text { Brainstorming, } \\
\text { improvement plan, } \\
\text { process sigma, material } \\
\text { flow synchronization } \\
\text { (flow diagram) }\end{array}$ \\
\hline Control & $\begin{array}{l}\text { How can we maintain the } \\
\text { improvements? }\end{array}$ & $\begin{array}{l}\text { SPC run chart, box plot, } \\
\text { histogram/frequency plots }\end{array}$ \\
\hline
\end{tabular}

firm would increase. The company A is having more capital productivity than company $\mathrm{B}$. But somehow, the company $\mathrm{B}$ is improving the performance by practicing SCM measures as evident from Fig. 5 which shows it is possible only because of reduction in inefficiency ratio.

The details of improved plan with necessary definitions and tools (based on DMAIC six sigma methodology) which the company B has adopted to improve SCM performance metrics in their supply chain network are presented in Table 4.

To initiate the improvement process, a supply chain network model is developed for measuring performance of various entities as shown in Fig. 6. The network consists of entities such as suppliers, manufacturer, warehouse, distributors and retailers through which raw materials are acquired, transformed and distributed to the customers. The objective of each entity is to make easy the scheduling of materials from upstream to downstream and, in turn, deliver products to the customers.
Various phases under DMAIC process are discussed as under:

\subsection{Define phase}

The aim of this phase is to determine the customer and process requirements that helps to define the scope of different metrics, i.e. total length of the supply chain, supply chain inefficiency ratio and supply chain working capital productivity for improving SCM performance. During define phase SIPOC (Supplier, Input, Process, Output and Customers), diagram (Fig. 7) was constructed to investigate the potential causes with respect to different metrics. As shown in the SIPOC diagram, manufacturing process starts from mixing of raw material and finishes with packaging and storage.

\subsection{Measure and analyse phase}

Data were collected with respect to different performance indices, i.e. total length of the supply chain, supply chain inefficiency ratio and supply chain working capital productivity to find out the problems in the network related to different entities. The data of different process defect such as (1) shrinkage (2) blending (3) grinding (4) thinning and dilution (5) filtration and finishing (6) packaging and storage were also collected to analyse the process performance.

In the analyse phase, brainstorming sessions were undertaken by team members in order to identify potential factors that could result in increasing the total length of the supply chain, inefficiency ratio and working capital productivity. Further, a cause analysis and validation plan to measure and analyse the potential causes related to different metrics with reference to different entities involved in supply chain network diagram are made. Based upon cause analysis and validation plan, the role of various entities involved in the network is discussed in the following paragraphs.

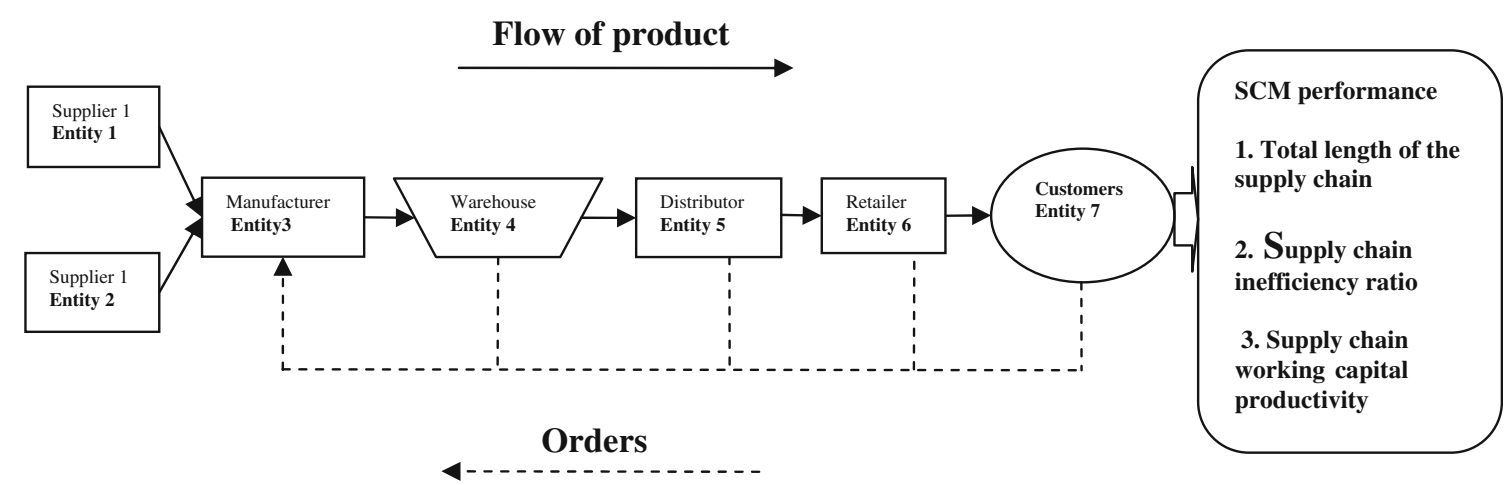

Fig. 6 Company supply chain network 


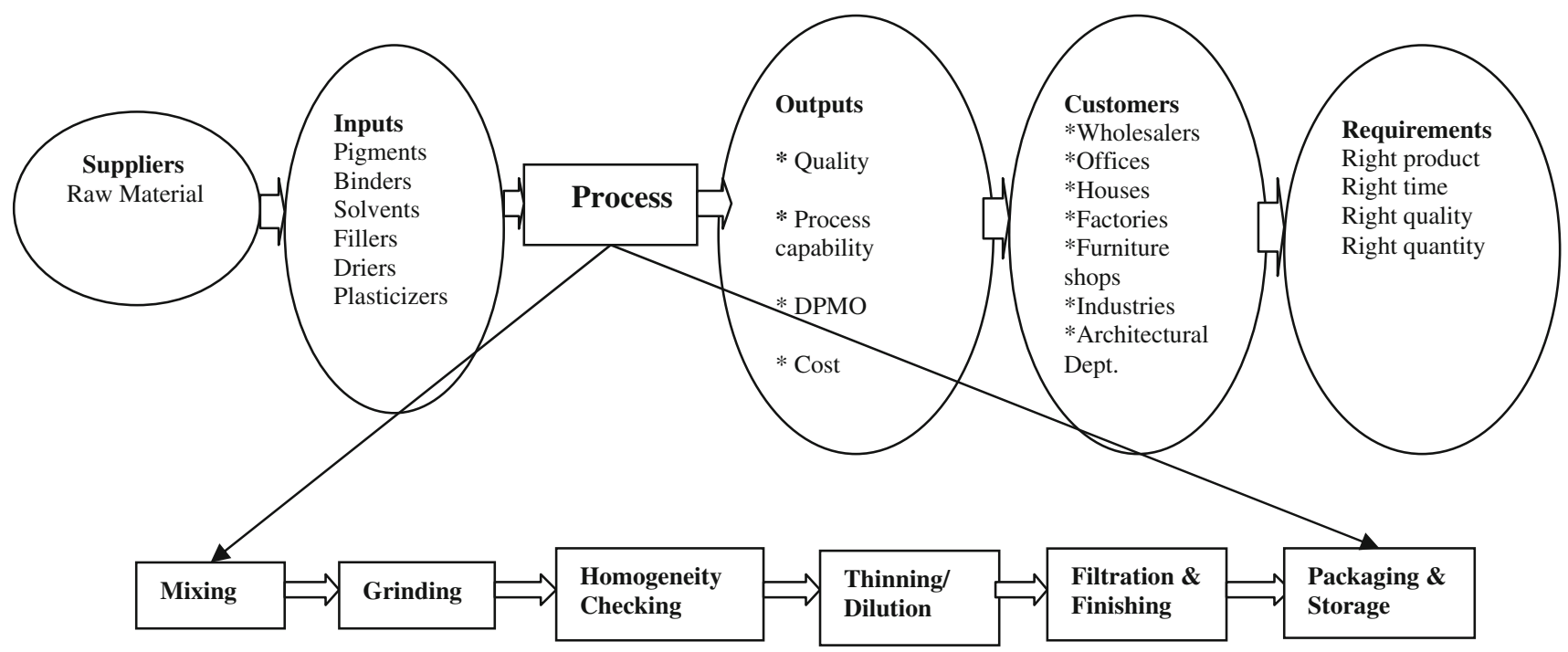

Fig. 7 SIPOC diagram

\subsubsection{Supplier to supplier variation}

Suppliers are the person or groups providing key materials, or other resources to the process. In our case, suppliers (entity 1 and 2) provide all the raw materials which are needed for paint manufacturing. To study the variation on the part of suppliers, the data of the number of orders not delivered to the manufacturer from supplier on specified time were collected and $t$ test was performed to compare the supplier to supplier variation. The details of descriptive statistics ( $t$ test) are given in Table 5. The Levene's $F$ test for equality of variances equals 0.987 and is statistically not significant at the 0.325 level. From the results, it is observed that supplier to supplier variation is significant and it is root cause, as significant value indicates that $p<0.05$, and therefore, it is significant at less than the 0.05 level for a two-tailed test, i.e. $t(58)=5.246, p=0.000$. So, a significant difference exists in the performance of suppliers in providing raw material and information to the manufacturer.

\subsubsection{Manufacturer}

Based on the historical records and observations, the different types of defects found in manufacturing process

Table 5 Independent sample $t$ test of suppliers

\begin{tabular}{llllllll}
\hline Group & Mean & $N$ & SD & $F$ value & $t$ value & $d f$ & $\begin{array}{l}\text { Sig. (two- } \\
\text { tailed) }\end{array}$ \\
\hline Supplier 1 & 22.10 & 30 & 3.8716 & 0.987 & 5.246 & 58 & 0.000 \\
Supplier 2 & 26.66 & 30 & 2.7833 & & & &
\end{tabular}

were categorized as (1) shrinkage (2) blending (3) grinding (4) thinning and dilution (5) filtration and finishing and (6) packaging and storage. In order to investigate the role of manufacturing, entity data related to the process defects were collected. Pareto diagram in Fig. 8 shows the overall distribution of defects with shrinkage as the major one which contributes to $59.76 \%$ of total defects. Other defects with considerable percentage were blending (14\%), grinding $(9.5 \%)$, thinning and dilution $(7.5 \%)$, filtration and finishing $(5.0 \%)$ and packaging and storage $(4.3 \%)$ [32]. This prioritization of defects using Pareto helps the team to focus on improvement actions that are linked with defects. To determine the overall distribution of percentage defective and the frequency of a range of defects, histogram plots are obtained, as shown in Fig. 9a-d, and statistical details such as mean, standard deviation are presented in Table 6, respectively. From the results, it is observed that process defects result in inefficient supply chain, increase in supply chain length (by not meeting the target at time) and reduction in capital productivity (loss due to rework, wastage and overhead costs).

\subsubsection{Warehouse}

Warehouse is the most important entity in the supply chain network. The efficiency and effectiveness in any distribution network in turn are largely determined by the functions of the nodes in such a network, i.e. warehouses. The functions performed by a warehouse include (1) receiving the goods from a source, (2) Storing the goods until they are required, (3) picking the goods when they are required and (4) shipping the goods to the appropriate user. It was suspected that there was a possibility of variation with 
Fig. 8 Pareto diagram for defects

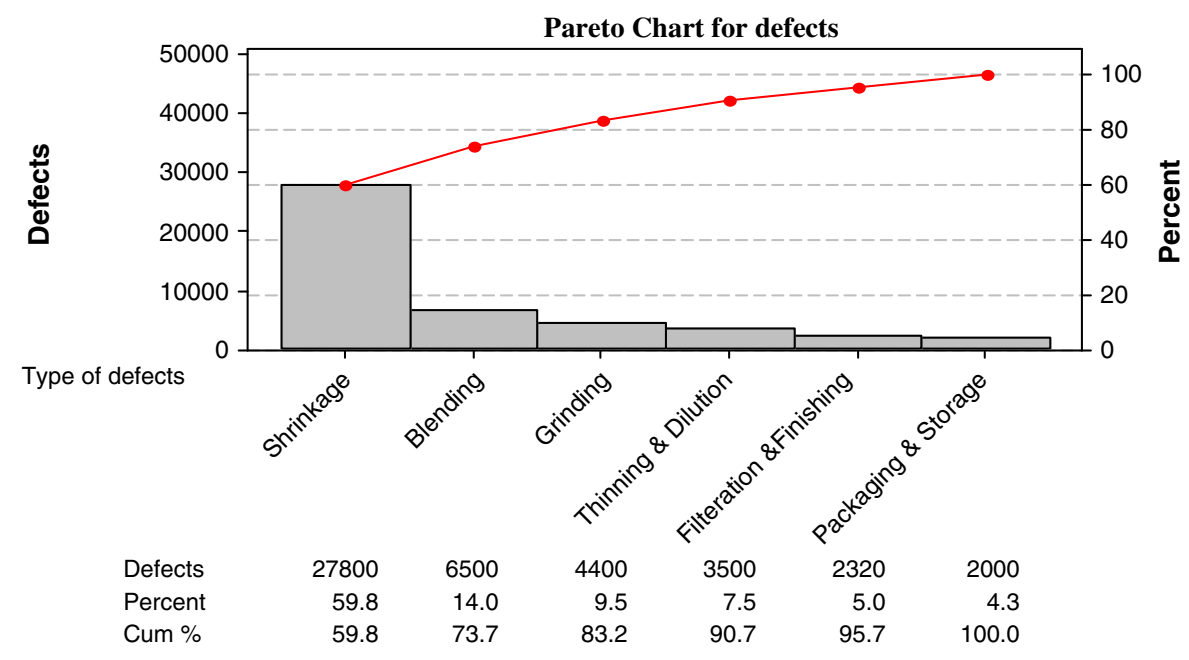

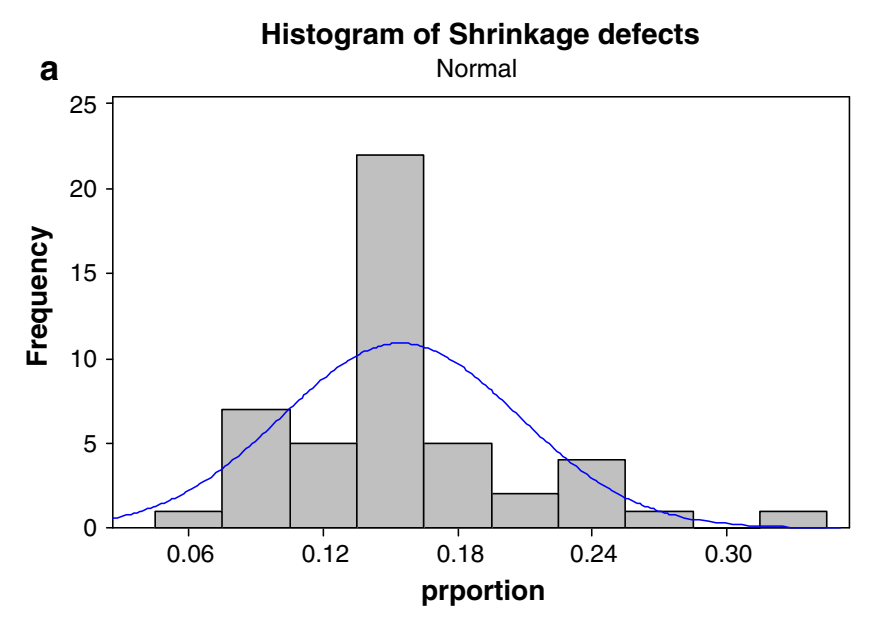

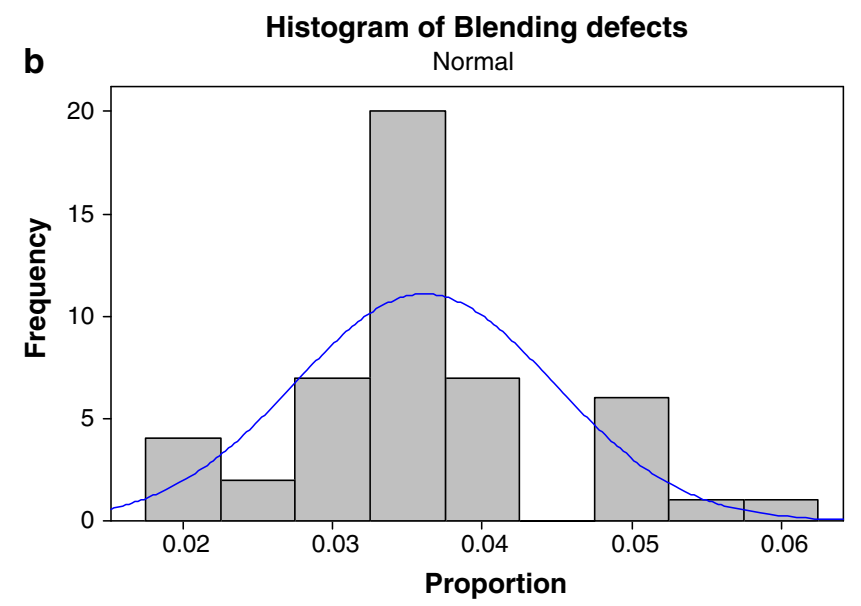

Histogram of Grinding defects
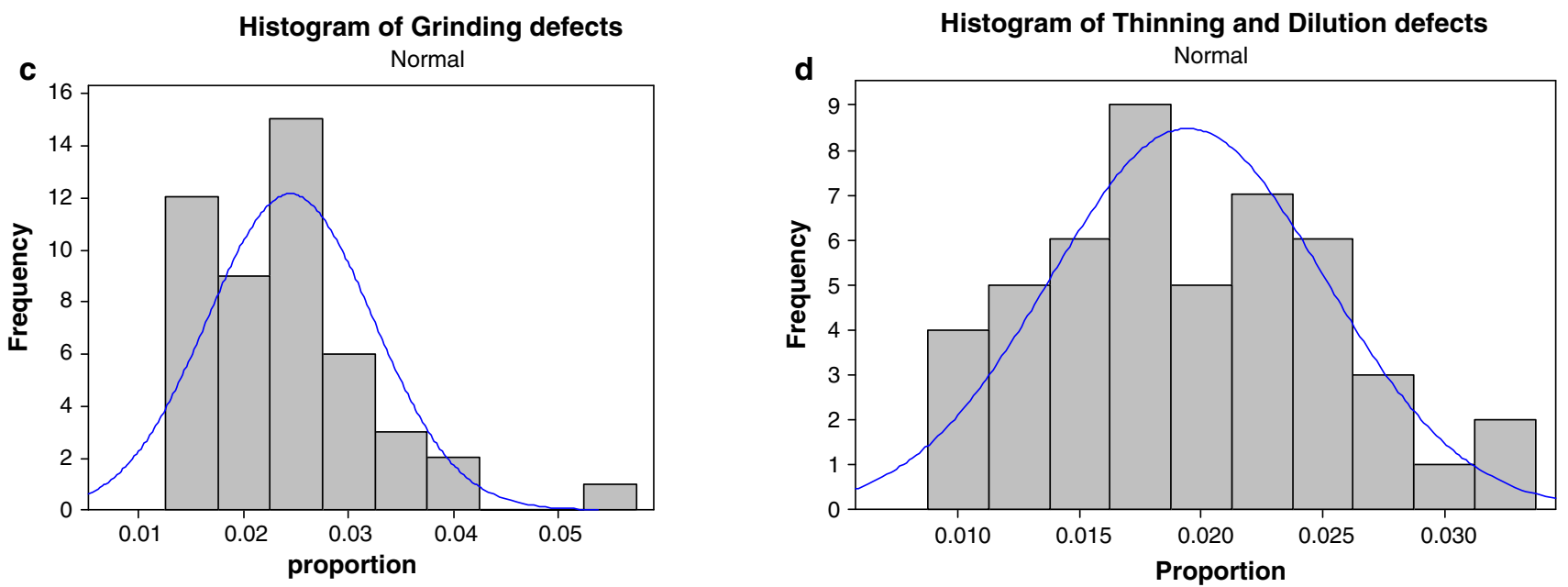

Fig. 9 Histogram of a shrinkage defects, $\mathbf{b}$ histogram of blending defects, $\mathbf{c}$ histogram of grinding defects, $\mathbf{d}$ histogram of thinning and dilution defect

respect to receiving order time and shipping order time with respect to the product and services. To test this possibility, an independent $t$ test was carried out to compare the warehouse performance based on receiving and shipping time. The details of descriptive statistics ( $t$ test) are given in Table 7. The Levene's $F$ test for equality of 
Table 6 Statistical details of defects

\begin{tabular}{lllll}
\hline $\begin{array}{l}\text { Descriptive } \\
\text { statistics }\end{array}$ & (Defects) & & & \\
\cline { 2 - 5 } & Blending & Shrinkage & Grinding & $\begin{array}{l}\text { Thinning and } \\
\text { dilution }\end{array}$ \\
\hline$N$ & 48 & 48 & 48 & 48 \\
Mean & 0.1544 & 0.0361 & 0.0244 & 0.0194 \\
SD & 0.0527 & 0.0086 & 0.0078 & 0.0056 \\
\hline
\end{tabular}

Table 7 Independent sample $t$ test of warehouse

\begin{tabular}{llllllll}
\hline Group & Mean & $N$ & SD & $F$ value & $t$ value & $d f$ & $\begin{array}{l}\text { Sig. } \\
\text { (two- } \\
\text { tailed) }\end{array}$ \\
\hline $\begin{array}{l}\text { Order time } \\
\begin{array}{c}\text { Shipping } \\
\text { time }\end{array}\end{array}$ & 6.0 & 30 & 1.0171 & 0.651 & 1.819 & 58 & 0.074 \\
\hline
\end{tabular}

variances equals 0.651 and is statistically not significant at the 0.423 level. From the results, it is observed that warehouse is not a root cause, as significant value indicates that $p>0.05$, and therefore, it is not significant at greater than the 0.05 level for a two-tailed test, i.e. $t(58)=1.819$, $p=0.074$. So, no significant difference exists in the performance of warehouse in receiving order time and shipping time.

\subsubsection{Distributor}

Since different distributor is also involved in supply chain network to fulfil the demand at specific time, it was suspected that there was possibility of distributor variation in received order time and delivery order time variation with respect to the product and services. To test whether product distributor variation affects and is a root cause of not fulfilling the order on time, an independent $t$ test was carried out. The details of $t$ test are given in Table 8 . The table contains descriptive statistics as well as $t$ test. The Levene's $\mathrm{F}$ test for equality of variances equals 0.626 and is statistically not significant at the 0.432 level. From the table, it was found that distributors are not the root cause of not fulfilling the order on time, as significant value indicates that $p>0.05$, and therefore, it is not significant at greater than the 0.05 level for a two-tailed test, i.e. $t(58)=1.733, p=0.088$.

\subsubsection{Retailer}

Retailer is the most important entity in the supply chain network. A retailer is a person who purchases a variety of goods in small quantities from different wholesalers, distributors and sells them to the crucial consumer. Retailers
Table 8 Independent sample $t$ test of distributor

\begin{tabular}{|c|c|c|c|c|c|c|c|}
\hline Group & Mean & $N$ & SD & $F$ value & $t$ value & $d f$ & $\begin{array}{l}\text { Sig. } \\
\text { (two- } \\
\text { tailed) }\end{array}$ \\
\hline Order time & 6.0333 & 30 & 0.8892 & 0.626 & 1.733 & 58 & 0.088 \\
\hline $\begin{array}{l}\text { Delivery } \\
\text { time }\end{array}$ & 6.4333 & 30 & 0.8976 & & & & \\
\hline
\end{tabular}

Table 9 Independent sample $t$ test of retailer

\begin{tabular}{llllllll}
\hline Group & Mean & $N$ & SD & $F$ value & $t$ value & $d f$ & $\begin{array}{l}\text { Sig. } \\
\text { two- } \\
\text { tailed) }\end{array}$ \\
\hline $\begin{array}{l}\text { Order time } \\
\begin{array}{l}\text { Delivery } \\
\text { time }\end{array}\end{array}$ & 7.0333 & 30 & 1.1885 & 2.210 & 1.350 & 58 & 0.182 \\
\hline
\end{tabular}

are the last entity in the supply chain of distribution from the producer to the consumer. So they play a vital role in fulfilling order on time to the customer. It was suspected that there was possibility of retailer's variation in received order time and delivery order time variation with respect to the product and services. To test whether product distribution variation affects the performance and a root cause of not fulfilling the order on time, an independent $t$ test was carried out to compare the retailer performance of producing the product and services to the customers. The details of $t$ test are given in Table 9. The table contains descriptive statistics as well as $t$ test. The Levene's $F$ test for equality of variances equals 2.210 and is statistically not significant at the 0.142 level. From the table, it was found that retailer is not the root cause of not fulfilling the order on time, as significant value indicates that $p>0.05$, and therefore, it is not significant at greater than the 0.05 level for a two- tailed test, i.e. $t(58)=1.350, p=0.182$.

\subsection{Improve and control phase}

The improvement efforts were planned to reduce variation in supply chain process on continuous scale Deming's P-DC-A cycle, i.e. (Plan- Do- Check, Act). The improvement actions include a mix of $5 \mathrm{~S}$ and total productive maintenance activities. Few of them are listed as under.

(1) Organization of the supply chain network: The organization of a supply chain network means strengthening the link between entities and their operational policies, making them more reliable and efficient aiming at delivering products to customer without any delay.

(2) Supplier development: Supplier development involves a long-term cooperative effort between the buying firms (manufacturer) and its suppliers (raw materials 
Table 10 Pearson's correlation between performance measures and SCM practices

\begin{tabular}{lcccc}
\hline Pearson correlation & SCM practices & Total length of supply chain & Supply chain inefficiency ratio & Working capital productivity \\
\hline Total length of supply chain & $0.846^{* *}$ & 1 & 1 & 1 \\
Supply chain inefficiency ratio & $0.769^{* *}$ & $0.671^{* *}$ & $-0.610^{* *}$ & \\
Working capital productivity & $-0.764^{* *}$ & $-0.681^{* *}$ & & \\
\hline
\end{tabular}

** Correlation is significant at the 0.01 level

providers), and is aimed at creating and maintaining a network of competent suppliers.

(3) Manufacturing Process: The manufacturing process should be improved by working on the causes that result in defects. For example, addition of solvents, pigments, in right quantity at right time will reduce the loss due to shrinkage defect.

(4) Coordination between entities: Coordination is one of the important drivers for successful implementation of SCM practices in a supply chain network. As lack of coordination in supply chain network will result in distortion of demand, i.e. bullwhip effect, it will result in increasing various costs, i.e. manufacturing cost, inventory cost, transportation cost, labour cost, and ultimately decrease in supply chain efficiency and capital productivity.

\section{Empirical analysis}

In order to examine the relationship between best SCM practices and SCM performance measures, empirical analysis has been done by formulating research hypothesis as discussed in Sect. 3. A structured questionnaire was designed as shown in "Appendix 2". To determine the reliability of the collected data and their scale using questionnaire, reliability assessment is done using Cronbach's alpha coefficient. All the alpha values were greater than 0.65 , and the data are considered reliable as suggested by $[27,31]$. In order to validate our hypothesis, $\mathrm{H} 1, \mathrm{H} 2$ and $\mathrm{H} 3$, we performed correlation and regression (Tables 10 and 11) between the SCM and performance measures. For hypothesis H4, H5 and H6, we performed $t$ test (Table 12) to see significant difference between firms that practises SCM and those without SCM exists or not.

\subsection{Empirical results}

Table 10 presents Pearson's correlation between the selected performance metrics. For interpretation of the correlation coefficient, we have examined the coefficient and its associated significant value $p$. Length and SCM practices show +ve correlation $(r=0.846)$. Similarly, inefficiency ratio and SCM are strongly correlated
Table 11 Regression of SCM with selected performance measures

\begin{tabular}{llllll}
\hline Performance measures & $F$ value & $P$ value & $R^{2}$ & $\beta$ & VIF \\
\hline $\begin{array}{c}\text { Total length of supply } \\
\text { chain }\end{array}$ & 146.606 & 0.000 & 0.717 & 0.469 & 2.315 \\
$\begin{array}{c}\text { Supply chain } \\
\quad \text { inefficiency ratio }\end{array}$ & 107.158 & 0.000 & 0.790 & 0.291 & 1.974 \\
$\begin{array}{c}\text { Supply chain working } \\
\text { capital productivity }\end{array}$ & 88.132 & 0.000 & 0.825 & -0.267 & 2.026 \\
\hline
\end{tabular}

$(r=0.769)$, and there is significant positive correlation exists between total length and inefficiency ratio, i.e. $(r=0.671, p<0.05)$. Therefore, both inefficiency ratio and total length are closely associated with each other. The productivity has also significant correlation between SCM $(r=0.764)$ and total length $(r=-0.681)$ as well as negative with the inefficiency ratio $(r=-0.610)$. As total length and efficiency increases, the productivity decreases and vice versa as well. The correlation coefficient between supply chain inefficiency ratio and total length of the supply chain is 0.671 and it is significant at the 0.01 level.

Further, to understand the relationship between SCM and performance measures, regression analysis (Table 11) has been done. The simple linear regression analysis was conducted to find out the relationship between SCM and performance measures of total length of supply chain. $R^{2}$ value was found out to be 0.717 which means that $71 \%$ of variance in performance was explained by the model which is highly significant as indicated by the $F$ value, i.e. 146.606, which indicates model is fit and valid. Significant value of 0.000 indicates that the regression is significant. There is no multivariate because no value is greater than or equal to the critical chi-square value of 13.8 at an alpha level of 0.001, if one examines the Mahalanobis (MAH1) distance value. Also, variance inflation factor (VIF) is 2.315 , so it shows that there is perfect correlation.

Secondly, for supply chain inefficiency ratio, the $R^{2}$ value is 0.790 , which suggests that $79 \%$ of variance was explained by the model which is highly significant as indicated by the $F$ value, i.e. 107.158, which indicates model is fit and valid. Significant value of 0.000 indicates that the regression is significant that there is useful linear model. 
Table $12 t$ test results for firm's performance measures with SCM practices

\begin{tabular}{|c|c|c|c|c|c|c|c|}
\hline \multirow[t]{2}{*}{ Metrics } & \multicolumn{4}{|c|}{ Group statistics } & \multicolumn{3}{|l|}{$t$ test } \\
\hline & Group & $N$ & Mean & SD & $t$ value & $d f$ & $\begin{array}{l}\text { Sig } \\
\text { (two-trailed) }\end{array}$ \\
\hline \multicolumn{8}{|l|}{ Total length (H4) } \\
\hline With SCM & 1 & 45 & 97.933 & 10.90 & - & 58 & 0.000 \\
\hline Without SCM & 2 & 15 & 146.66 & 19.51 & 12.108 & 58 & 0.000 \\
\hline \multicolumn{8}{|c|}{ Inefficiency ratio (H5) } \\
\hline With SCM & 1 & 45 & 0.061 & 0.00758 & & 58 & 0.000 \\
\hline Without SCM & 2 & 15 & 0.0833 & 0.00900 & -9.152 & & \\
\hline \multicolumn{8}{|c|}{ Working capital productivity (H6) } \\
\hline With SCM & 1 & 45 & 8.488 & 1.2902 & & & \\
\hline Without SCM & 2 & 15 & 4.866 & 1.5055 & 9.031 & & \\
\hline
\end{tabular}

Thirdly, for the supply chain, working capital productivity value of $F$ is 88.132 , and $R^{2}$ is 0.825 , which suggests that there is $82.5 \%$ of variance in performance measure, i.e. working capital productivity. Significant value of 0.000 indicates that the regression is significant that there is a useful linear model. The VIF is 2.026, so there is perfect correlation between them.

The relationship between the dependent and independent variables can be expressed in form of equation as:

$$
\begin{aligned}
& y=a+\beta_{1} x_{1}+\beta_{2} x_{2}+\beta_{3} x_{3} \\
& y=0.089+0.469 x_{1}+0.291 x_{2}-0.267 x_{3}
\end{aligned}
$$

where $\mathrm{y}=$ supply chain management performance $\mathrm{x}_{1}=$ total length of the supply chain $\mathrm{x}_{2}=$ supply chain Inefficiency Ratio $\mathrm{x}_{3}=$ supply chain working capital productivity.

\section{Discussions}

In the study, the authors have discussed two independent approaches to evaluate SCM performance, one based on company data and another based upon empirical analysis. Data related to various performance metrics, i.e. (1) total length of the supply chain; (2) supply chain inefficiency ratio and (3) supply chain working capital productivity were collected and analysed to benchmark the SCM performance of two companies. Further, an empirical analysis has been done by formulating research hypothesis based upon critical review of literature studies. The findings based upon statistical analysis clearly support our hypothesis $\mathrm{H} 1, \mathrm{H} 2$ and H3, i.e. following SCM practices firms improve their SCM performance. The beta values obtained by regression analysis help us to measure how strongly each performance measure influence the SCM performance.

We also performed $t$ test to see whether significant differences between firms that practise SCM and those without SCM exists or not and to test hypothesis $\mathrm{H} 4, \mathrm{H} 5$ and H6. The companies following SCM practices are defined as group 1 with $N=45$, and those not following SCM practices are defined as group 2 with $N=15$. Column 3 and 4 in Table 12 show the mean and standard deviation of performance metrics with respect to both SCM and non-SCM companies. We performed Levene's test for equality of variance, as $p>0.05$, and therefore, we can say that variance is relatively equal for firm which following SCM and those without SCM. The $t$ value, $d f$ and twotailed significance for the equal variance to determine whether significant difference between SCM and non-SCM firms exists or not are presented in Table 12.

As evident from results, there is a significant difference between two groups of firm with reference to the three metrics exists, as significant value indicates that $p<0.05$, and therefore, it is significant. For a two-tailed test, i.e. $t(58)=-12.108,-9.152$ and 9.031, $p=0.000$. This result is also supported by Bowersox et al. [8], Martin and Patterson [30] in literature. So, our Hypothesis H4, H5 and H6 are tested by $t$ test. Thus, we can conclude that the firms which practise SCM outperform than those without SCM.

The results of the work bring forward the following theoretical implications.

1. In order to attain competitive positioning, a firm can benchmark its own profile with that of its competitors in order to establish where it stands in terms of supply chain length, inefficiency and capital productivity. In the study, the benchmarking and performance measurement using selected metrics help to investigate the causes/entities in supply chain network which result in low SCM performance. For instance, the use of DMAIC in supply chain network shown in Fig. 6 helps to identify the entity, i.e. supplier which may result in increase in supply chain length with statistics, i.e. $t(58)=5.246, p=0.000$.

2. Companies that follow SCM practices manage their supply chain length and hence reduce inefficiency ratio 
and increase overall capital productivity than those without SCM. For SCM companies, the measures supply chain length and inefficiency ratio had average, i.e. 97.933, 0.061 lesser than those without SCM, i.e. 146.66, 0.0833, respectively. Also, the average of overall capital productivity is more, i.e. 8.488 with SCM as compared to 4.866 without SCM. Thus, adoption of SCM practices by companies promote efficient management of supply chain which can lead to enhanced competitive advantage and improved organizational performance. Studies conducted by authors support the findings in this regard [29, 33, 45].

\section{Conclusions}

Our findings indicate that the firms that practise the SCM perform better than those without SCM. Statistical tests confirm that good SCM practices are able to decrease the length of the supply chain and reduce supply chain inefficiency ratio and increase the capital productivity. Empirical analysis supports the positive correlation between the SCM practices and SCM performance metrics. Also, multiple regressions were used to determine the impact of SCM practices on firm performance. Regression model shows that the maximum contributor for the SCM performance is total length of the supply chain, where the coefficient is (0.469) followed by supply chain inefficiency ratio (0.291). The results are supported by studies conducted by Martin and Patterson, [30] and Sriyogi [43] in which they concluded that firms that manage their internal supply chain processes in an efficient manner will have lower levels of inventory and the use of internal firm performance measurement, inventory and cycle time offer the best metrics for positioning the company into a supply chain network.

Although the study presents an important contribution first by developing a framework for benchmarking/measuring an internal supply chain performance of the firm and then by empirically testing the findings based on research hypothesis, researchers can attempt to establish similar framework of SCM metrics for some other industrial sectors such as construction, food and agriculture and textile industry. According to Ren et al., [37], the global competition worldwide forces the business houses to look at their supply chain in order to reduce both costs and time involved in their processes. It is therefore advised that future research should study the relationship between contextual factors, i.e. (1) size of the company (2) field of operations, i.e. industrial or service sector (3) priorities for competitive positioning that affect adoption of SCM practices. Our results also demonstrate relatively low performance level of non-SCM companies. So, work can be further extended to find out the barriers which result in low performance level with respect to selected metrics.

Open Access This article is distributed under the terms of the Creative Commons Attribution License which permits any use, distribution, and reproduction in any medium, provided the original author(s) and the source are credited.

\section{Appendix 1}

See Table 13

Table 13 Indicators data for SCM performance measurement

\begin{tabular}{|c|c|c|c|c|c|c|c|c|c|}
\hline \multicolumn{10}{|c|}{ Total length supply chain } \\
\hline & $\mathrm{RM}$ & CRM & SFG & $\mathrm{CP}$ & FG & $\mathrm{CS}$ & DRM & DWIP & DFG \\
\hline \multicolumn{10}{|l|}{ Company A } \\
\hline FY 05-06 & 107.96 & 1351.7 & 19.39 & 163 & 91.18 & 2081.74 & 29.152 & 43.419325 & 33.520372 \\
\hline FY 06-07 & 124.97 & 1660.71 & 25.73 & 190.82 & 256.35 & 2517.09 & 27.4665 & 49.2162 & 37.17298 \\
\hline FY 07-08 & 190.82 & 1956.13 & 29.95 & 214.45 & 287.16 & 3026.04 & 35.6056 & 50.9757 & 34.63715 \\
\hline FY 08-09 & 195.08 & 2606.93 & 36.25 & 256 & 281.63 & 3916.19 & 27.3134 & 51.68457 & 26.248714 \\
\hline FY 09-10 & 280.1 & 2840.24 & 39.51 & 296.29 & 408.16 & 4334.76 & 35.9957 & 48.6724 & 34.3683 \\
\hline \multicolumn{10}{|l|}{ Company B } \\
\hline FY 05-06 & 71.98 & 643.44 & 13.78 & 70.66 & 116.81 & 878.38 & 40.83162 & 71.1817 & 48.53895 \\
\hline FY 06-07 & 93.9 & 791.51 & 16.12 & 75.95 & 147.32 & 1044.11 & 43.3014 & 77.4693 & 51.5001 \\
\hline FY 07-08 & 89.56 & 886.65 & 15.82 & 88.13 & 151.58 & 1204.34 & 36.8684 & 65.5202 & 45.9394 \\
\hline FY 08-09 & 72.76 & 1027.64 & 14.09 & 96.7 & 167.46 & 1383.55 & 25.8430 & 53.1835 & 44.1783 \\
\hline FY 09-10 & 94.03 & 1093.3 & 17.05 & 106.5 & 174.96 & 1510.34 & 31.39207 & 58.4342 & 42.2821 \\
\hline
\end{tabular}


Table 13 continued

\begin{tabular}{|c|c|c|c|c|}
\hline \multicolumn{5}{|c|}{ Supply chain inefficiency ratio } \\
\hline & DC & INV & ICC & NS \\
\hline \multicolumn{5}{|l|}{ Company A } \\
\hline FY 05-06 & 95.02 & 318.53 & 0.2 & 2447.78 \\
\hline FY 06-07 & 100.23 & 407.05 & 0.2 & 2953.37 \\
\hline FY 07-08 & 139.33 & 508.11 & 0.2 & 3595.53 \\
\hline FY 08-09 & 170.37 & 512.97 & 0.2 & 4510.12 \\
\hline FY 09-10 & 196.96 & 727.77 & 0.2 & 5367.72 \\
\hline \multicolumn{5}{|l|}{ Company B } \\
\hline FY 05-06 & 45.8 & 202.57 & 0.2 & 979.97 \\
\hline FY 06-07 & 50.2 & 257.34 & 0.2 & 1159.88 \\
\hline FY 07-08 & 53.27 & 256.96 & 0.2 & 1339.4 \\
\hline FY 08-09 & 59.02 & 254.31 & 0.2 & 1510.96 \\
\hline FY 09-10 & 50.32 & 286.04 & 0.2 & 1686.52 \\
\hline \multicolumn{5}{|c|}{ Supply chain working capital Productivity } \\
\hline & INV & AR & $\mathrm{AP}$ & NS \\
\hline \multicolumn{5}{|l|}{ Company A } \\
\hline FY 05-06 & 318.53 & 185.1 & 183.68 & 2447.78 \\
\hline FY 06-07 & 407.05 & 233.96 & 267.35 & 2953.37 \\
\hline FY 07-08 & 508.11 & 251.9 & 375.73 & 3595.53 \\
\hline FY 08-09 & 512.97 & 311.02 & 358.51 & 4510.12 \\
\hline FY 09-10 & 727.77 & 331.43 & 571.71 & 5367.72 \\
\hline \multicolumn{5}{|l|}{ Company B } \\
\hline FY 05-06 & 202.57 & 109.51 & 98.06 & 979.97 \\
\hline FY 06-07 & 257.34 & 143.52 & 100.09 & 1159.88 \\
\hline FY 07-08 & 256.96 & 158.44 & 110.8 & 1339.4 \\
\hline FY 08-09 & 254.31 & 180.38 & 117.5 & 1510.96 \\
\hline FY 09-10 & 286.04 & 204.73 & 194.2 & 1686.52 \\
\hline
\end{tabular}

$R M$ raw material inventory, $C R M$ cost of raw material, $S F G$ semi-finished goods inventory, $C P$ cost of production, $F G$ finished goods inventory, $C S$ cost of sales, $D R M$ days of raw material, $D W I P$ days of work in process, $D F G$ days of finished goods inventory, $D C$ distribution cost, $I N V$ inventories level, $I C C$ inventory carrying cost, $N S$ net sales, $A R$ account receivables, $A P$ account payables, $S W C P$ supply chain working, capital productivity 


\section{Appendix 2}

\section{QUESTIONNAIRE}

\section{General Information}

Name of organization

Please indicate the number of employees in your organization. $\begin{array}{llll}0 \leq 50 \quad \square & >50 \leq 100 & \square \\ >150 \leq 200 \square & >200 \leq 250 \quad \square & \\ \square & & >250 \leq 300 \square\end{array}$

\section{For empirical analysis}

Q.1 How much day's raw material takes to arrive in Inventory from vendor? 10 days $\square \quad 20$ days $\square \quad \square \quad 30$ days

40 days $\square \quad 50$ days $\square \quad \square$ above 50 days

Q.2 How much days work in process takes in Inventory?
10 days
20 days
$\square \quad 30$ days
40 days
50 days
above 50 days

Q.3 How much days finished goods takes in Inventory?
10 days
20 days
30 days
40 days
50 days
above 50 days

Q.4 How much is your Inventory carrying cost per annum?

$\begin{array}{llllll}0.05 & \square & 0.10 & \square & 0.15 & \square \\ 0.20 \quad \square & 0.25 & \square & \text { above } .25 & \square\end{array}$

Q.5 How much is your distribution cost per annum?

$\begin{array}{lllll}50 \mathrm{cr} & \square & 100 \mathrm{cr} & \square & 150 \mathrm{cr}\end{array}$

Q.6 How much is your net sales per annum?

$\begin{array}{lll}\text { Below 1000cr } \square \quad 2000 \mathrm{cr} & \square \quad 3000 \mathrm{cr} \\ 4000 \mathrm{cr} & \square \quad 5000 \mathrm{cr} \quad \square & \square\end{array}$

Q.7 How much is your supply chain inefficiency ratio?

$\begin{array}{lllll}0.05 & \square & 0.06 & \square & 0.07 \\ 0.08 & \square & 0.09 & \square & \text { above } .09\end{array}$

Q.8 How much is your a/c receivable in your current asset per annum? $100 \mathrm{cr} \quad \square$ 150cr $\square$ 200cr

$250 \mathrm{cr} \quad \square \quad 300 \mathrm{cr} \quad \square$ above $300 \mathrm{cr}$

Q.9 How much is you're a/c payable in your current liability per annum? $100 \mathrm{cr} \quad \square \quad 150 \mathrm{cr} \quad \square \quad 200 \mathrm{cr}$

250cr $\square \quad 300 \mathrm{cr} \quad \square \quad$ above $300 \mathrm{cr}$

Q.10- How much is your working capital per annum? $100 \mathrm{cr} \quad \square \quad 150 \mathrm{cr} \quad \square \quad 200 \mathrm{cr}$

250cr $\square$ 300cr above 300cr

Q.11- How much is your supply chain working capital productivity

$\begin{array}{llllll}4 & \square & 7 & \square & 8 & \square \\ 9 & \square & 10 & \square & 11 & \square\end{array}$

\section{References}

1. Akyuz GA, Erkan TE (2010) Supply chain performance measurement: a literature review. Int J Prod Res 48(17):5137-5155

2. Arlbjorn JS, de Haas H, Munksgaard KB (2011) Exploring supply chain innovation. Logist Res 3(1):3-18

3. Barber E (2008) How to measure the value in value chains. Int J Phys Distrib Logist Manag 38(9):685-698

4. Basnet C, Corner L, Wiense J, Tan K (2003) Benchmarking supply chain management practice in New Zealand. Supply Chain Manag Int J 8(1):57-64

5. Beamon BM (1998) Supply chain design and analysis: models and methods. Int J Prod Econ 55(3):281-294

6. Bhagwat R, Sharma MK (2007a) Performance measurement of supply chain management: a balance scorecard approach. Comput Ind Eng 53(1):43-62

7. Bhagwat R, Sharma MK (2007b) Performance measurement of supply chain management using the analytical hierarchy process. Prod Plan Control 18(8):666-680

8. Bowersox DJ, Closs DJ, Keller SB (2000) How supply chain competency leads to business success. Supply Chain Manag Rev 4(4):70-78

9. Brandenburg M, Seuring S (2011) Impact of supply chain management on company value: benchmarking companies from the fast moving consumer goods industry. Logist Res 3(4):233-248

10. Cai J, Liu X, Zhihui X, Liu J (2009) Improving supply chain performance management: a systematic approach to analyzing iterative KPI accomplishment. Decis Support Syst 46(2):512-521

11. Cao D, Leung LC, Law JS (2008) Modifying inconsistent comparison matrix in analytic hierarchy process: a heuristic approach. Decis Support Syst 44(4):944-953

12. Carvalho H, Azevedo SG, Cruz-Machado V (2012) Agile and resilient approaches to supply chain management: influence on performance and competitiveness. Logist Res 4(1/2):49-62

13. Chong AYL, Ooi KB (2008) Adoption of inter-organizational system standards in supply chains: an empirical analysis of Rosetta Net standards. Ind Manag Data Syst 108(4):529-547

14. Christopher M, Towill DR (2001) An integrated model for the design of agile supply chain. Int J Phys Distrib Logist Manag 31(4):235-246

15. Dangayach GS, Deshmukh SG (2003) Evidence of manufacturing strategies in Indian industry: a survey. Int $\mathrm{J}$ Prod Econ 83:279-298

16. Elmuti D (2002) The perceived impact of SCM on organization effectiveness. J SCM Global Rev Purch Supply 38(3):49-57

17. Epstein MJ, Weisner PS (2001) Good neighbors: implementing social and environmental strategies with the BSC, Balanced Scorecard Report, Reprint Number B0105C 33. Harvard Business School, Cambridge

18. Folan P, Browne J (2005) A review of performance measurement: towards performance management. Comput Ind 56(7):663-680

19. Gilmour P (1999) Benchmarking supply chain operations. Int J Phys Distrib Logist Manag 5(4):259-266

20. Gomes CF, Yasin MM, Lisboa JV (2004) A literature review of manufacturing performance measures and measurement in an organizational context: a framework and direction for future research. J Manuf Technol Manag 15(6):511-530

21. Gunasekaran A, Patel C, Tirtiroglu E (2001) Performance measures and metrics in a supply chain environment. Int J Oper Prod Manag 21(1/2):71

22. Gunasekaran A, Patel C, McGaughey RE (2004) A framework for supply chain performance measurement. Int $\mathrm{J}$ Prod Econ 87(3):333-347 
23. Hanman S (1997) Benchmarking your firm's performance with best practice. Int J Logist Manag 8(2):1-18

24. Hudson M, Lean J, Smart PA (2001) Improving control through effective performance measurement in SMEs. Prod Plan Control 12(8):804-813

25. Kaplan RS, Norton DP (1992) The Balanced scorecard measures that drive performance. Harv Bus Rev 70(1):71-79

26. Keebler JS, Plank RE (2009) Logistics performance measurement in the supply chain: a benchmark. Benchmark Int J 16(6):785-798

27. Koh SC, Demirbag M, Bayraktar E, Tatoglu E, Zaim S (2007) The impact of supply chain management practices on performance of SMEs. Ind Manag Data Syst 107(1):103-124

28. Lambert DM, Pohlen TL (2001) Supply chain metrics. Int J Logist Manag 12(1):1-19

29. Li S, Ragu-Nathan B, Ragu-Nathan TS, Rao SS (2006) The impact of supply chain management practices on competitive advantage and organizational performance. Int $\mathbf{J}$ Manag Sci Omega 32(2):107-124

30. Martin RP, Patterson PW (2009) On measuring company performance within a supply chain. Int J Prod Res 47(9):2449-2460

31. Martinez ACL (2008) Self-reported reading strategy use among Spanish university students of English. RESLA 21:167-179

32. Mishra P and Sharma RK (2011) A framework imbibing leagile and six -sigma culture to improve SCM performance. Proceedings of the International Conference on "Advances in supply Chain and Manufacturing Management", Kharagpur, India, December 16-18

33. Mohanty RP, Desmukh SG (2000) Reengineering of a supply chain management system: a case study. Prod Plan Control 11(1):90-104

34. Neely A, Gregory M, Platts K (2005) Performance measurement system design. Int J Oper Prod Manag 25(12):1228-1263

35. Persoon F, Araldi M (2009) The development of a dynamic supply chain analysis tool - Integration of SCOR and discrete event simulation. Int J Prod Econ 121(2):574-583

36. Paranjape B, Rossiter M, Pantono V (2006) Performance measurement systems: successes, failures and the future-a review. Meas Bus Excell 10(3):4-14
37. Ren J, Yusuf YY, Burns ND (2009) A decision support framework for agile enterprise partnering. Int $\mathbf{J}$ Adv Manuf Technol 41(1):180-192

38. Shah J, Singh N (2001) Benchmarking internal supply chain performance: development of a framework. J Supply Chain Manag 37(1):37-47

39. Shah J (2009) Supply chain management. Text and cases. Pearson Education, New Jersey

40. Shepherd C, Günter H (2006) Measuring supply chain performance: current research and future directions. Int $\mathrm{J}$ Product Perform Manag 55(3/4):242-258

41. Singh A, Narain R, Yadav RC (2006) Benchmarking and performance measurement of supply chain management practices: a survey of Indian organizations. Int $\mathbf{J}$ Serv Oper Manag 2(4):313-334

42. Soni G, Kodali R (2010) Internal benchmarking for assessment of supply chain performance. Benchmarking Int J 17(1):44-76

43. Sriyogi K (2012) Internal benchmarking of supply chain performance measures evidence from selected organizations. IUP J Supply Chain Manag 9(1):40-71

44. Sridharan UV, Caines WR, Patterson CC (2005) Implementation of supply chain management and its impact on the value of firms. Supply Chain Manag Int J 10(4):313-318

45. Vaart V, Donk V (2008) A critical review of survey-based research in supply chain integration. Int $\mathrm{J}$ Prod Econ 111(1):42-55

46. Wong WP, Wong KY (2008) A review on benchmarking of supply chain performance measures. Benchmarking Int $\mathrm{J}$ $15(1): 25-51$

47. Wouters M, Wilderom C (2008) Developing performance measurement systems as enabling formalization: a longitudinal field study of a logistics department. Account Organ Soc 33(4/ 5):488-516

48. Wouters M (2009) A development approach to performance measures - results from a longitudinal case study. Euro Manag J 27(1):64-78 